\title{
Application of innovative Technology in children furniture design
}

\author{
Jun han ${ }^{1, \text { a }}$, Jun li ${ }^{1, \mathrm{~b}}$, YangYang jiang ${ }^{1, \mathrm{c}, \text { LuLu wang }}{ }^{1, \mathrm{~d}}$ \\ ${ }^{1}$ Wuhan Institute of Technology art design college, Wuhan, Hubei, China
}

\begin{abstract}
Digital Innovative design is everywhere. With the opening of China's two-child policy, children's furniture market is gradually expanding, and people's demand for children's furniture is also increasing. Choose a suitable for children's health, happiness, sustainable furniture, become the focus of attention of parents[1]. Children's furniture needs to be broken into old ones and innovated beyond them, so as to bring benefits to the market.
\end{abstract}

\section{Several characteristics of cognition}

\subsection{Attention characteristics}

Attention characteristics are divided into attention finiteness and attention selectivity. The limitation of attention is that the attention of children aged 2-6 years is mainly influenced by the available energy around them; The selectivity of attention is that children between 2 and 6 years old are influenced by their will at that time and their evaluation of the energy required to complete the task, which means that stimulation is an interesting, satisfying and difficult task, which will attract the attention of parents.

\section{- The limitation of attention}

The most important reason for the limitation of attention is that children pay attention to the things that their age group will pay attention to and only pay attention to the things they like or the people and things they care about. The influence of people and things around them is also huge. Children who grow up in different environments are ultimately different. The things that family members pay attention to will also become their choice of things to pay attention to. In order to protect children from external harm, parents only let children live in the same environment every day without the influence of external things, which will also contribute to the limitation of attention.

- Selective attention

Children in the same playground to choose the play items are also very different, just like in the supermarket to choose their favorite food, there may be the same selection, but different tastes. With the progress of society, all kinds of things are presented to children, which promotes the selectivity of attention. With the emergence of more and more new things, children have some influence on their choices.

\subsection{Reaction characteristics}

In the man-machine environment system, the reaction characteristic of children is to receive information from the machine through the sensory organs, understand its meaning and explain it, or to make a decision by first calculating and then comparing the result with the past experience and strategy, and the user manipulates the manipulator of the machine by controlling the organ. Therefore, in the human-machine interface, response is based on information processing and subsequent actions after decisions are made.

\section{Principles of cognitive theory}

\subsection{Principle of clarity}

In order to improve the operation quality and work efficiency of users, interface design should be simplified as far as possible, and unnecessary complex parts should be removed. In order to avoid excessive competitive design of attention, which will lead to the failure and failure of human machinery. An overload of information can also distract users and affect usage. Therefore, the principle of clarity of human-machine interface will make it more convenient for children to operate.

\subsection{Consistency Principle}

A consistent human-computer interface allows users to transfer existing knowledge and experience to new tasks, learning and using the system faster. Children become more comfortable with another similar product based on their own experience with it, eliminating the unnecessary learning process.

a12474681@qq.com
b1518372923@qq.com
c1607547474@qq.com
d812594142@qq.com

(C) The Authors, published by EDP Sciences. This is an open access article distributed under the terms of the Creative Commons Attribution License 4.0 (http://creativecommons.org/licenses/by/4.0/). 


\subsection{Principle of learnability}

Learnability, by definition, is easy to learn. No matter what level of education, language skills or concentration they have, it is easier for users to understand how the products are used, which is more important for the design of children's products.

\section{Market status analysis}

In December 1988, the Central Committee of the Communist Party of China issued the Notice on The Reform and Strengthening of Moral Education in Primary and Secondary Schools. Through this document, we can know that childhood plays an important role in the whole period. In this process, education, habit cultivation and moral integrity can be quickly accepted.

From 2009 to 2011, the number of newborns in China was 48.1 million, and the number of newborns in urban areas was about 24 million, which was corresponding to the number of children aged 4-6 years in 2015. According to the research results of Kumanju, it is estimated that about $10 \%$ of families in China have bought children's furniture, and the average price of each set of children's furniture is 11,500 yuan per set. Then the corresponding scale of this part of demand in 2015 is about 27 billion yuan. To sum up, the current scale of China' s children' s furniture market is about 32 billion yuan.

Nowadays, with the increasingly excellent living conditions and improved living conditions, consumers have a growing demand for children's products. Although the time of children furniture in China is relatively slow and the market development is still in the stage of development, it has great potential in the long run. Consumers have invested a great deal of enthusiasm and money in furniture products for children's use, and their functional requirements are not high. Not only need to make a change in the shape, but also need a certain aesthetic. Children's furniture full of childlike interest and high interactive for children to create a good environment for children to grow up, so the demand for children's furniture gradually expanded in the market. According to a survey, there are more than 300 million children under the age of 16 in China, accounting for about a quarter of the country's population, and 74 percent of urban children have their own independent rooms, which is tantamount to a gold mine yet to be mined.

From the perspective of the development environment of children furniture market, the overall operation situation of children furniture, the current situation of children furniture market operation and the competitive pattern of children furniture market are studied, and the children furniture market is very promising.

Although China' s children' s furniture market started late, the market development is still in the beginning stage, but it has great potential. In the present stage children furniture market, innovative children furniture is more favored by the public, material, color, size and function are also taken into consideration. The design requirements of children' s furniture also become higher with the demand of the public, and designers have also made reasonable improvements to children's furniture.

Cognitive attribute of children' $s$ furniture is characterized by its ability to make children aware of cognitive attributes while using products. At present, designers are trying to design novel and reasonable functions and structures, so as to improve the safety and convenience of the use of products. With the improvement of human living conditions, many children have their own space since childhood. Children's furniture market is heating up, and businesses are investing in children's furniture market. With the continuous innovation of children' s furniture, consumers' requirements for children's furniture are also becoming higher and higher.

\section{Children's furniture design based on cognitive attributes}

\subsection{From the perspective of cognitive psychology}

Children between the ages of 2 and 6 are in the basic cognitive stage, which is also a very important period, so they need to combine their actual purchase. Three stages are analyzed from the perspective of cognitive psychology: in the early stage, children are attracted by the shape of this product as soon as they see it; In the middle, can not help but want to fumble and grasp the operation; In the later stage, the corresponding operation will be carried out according to the set rules. Children aged 2-6 years old are mentally energetic, active and active; Competitive and good at exploring new things; I have strong learning ability and certain thinking ability. I am eager to accompany and depend on my parents, and I need their guidance and help to complete various activities in my life. ${ }^{1}$ So it would be great if the product could involve parents.

From the perspective of vision, there are mainly two aspects of vision and color discrimination. After the age of 3 , children will be more and more fond of reading books with pictures, and their recognition of colors will be stronger and stronger. Some basic colors, such as red, yellow and blue, will also be able to be clearly distinguished. However, for some of the more difficult to identify, the two colors of the indirect color is still difficult.

Around the age of three, children will gradually develop the desire for artistic expression, and their artistic ability will develop from being in a state of stupor to a state of symbol. Although adults may not understand what they are painting, they will be satisfied with what they are painting. They like to supplement their painting with language while painting. What they are painting is the object they imagine.

Children's desks and chairs are necessary for every child, so giving cognitive attributes on children's desks and chairs can not only retain the basic functions of desks and chairs, but also turn them into products combining play and storage, which can kill many birds with one stone. 


\subsection{Reflections on children's Furniture design}

- Think from the perspective of child psychology

For parents, the safety of children is always the first priority. Safety will be considered before choosing products for children, followed by quality, shape, function, structure, etc. The age of 2-6 is a critical period for children's learning and cognition. Parents expect their children to develop good cognition during this important period, which will have a great impact on their future growth. Children between the ages of 2 and 6 should buy cute products that are suitable for this age group.

When choosing children's desks and chairs, the combination of the three aspects of storage, interest and cognition and children's desks and chairs will make it easier for the public to accept.

- Man-machine factor analysis

Height and weight of children at different ages are different. Height and weight of children are inevitable factors to be considered when designing products. By studying the height of different age groups, this chart shows the growth of children from birth to the age of 6 .

- From the perspective of bionics

Based on people's understanding of nature, bionic design combines design inspiration with art, and through advanced science and technology, finally obtains works that complement each other between modern industry and nature[3]. After referring to many pictures of plants and animals, the author finally chose hippopotamus as the prototype of the product modeling to attract the attention of children with its simple and honest and lovely image.

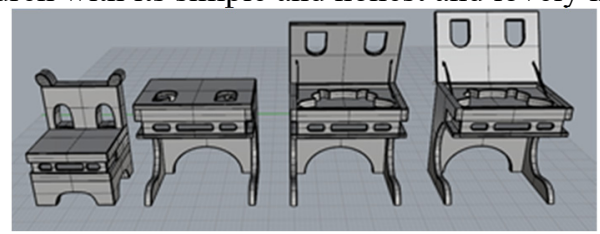

Figure 1 Modeling figure

Children bionic furniture is composed of table and chair, as shown in Figure 1, the model is designed according to hippo, showing the simple and honest and lovely image of children aged 2-6 years, vivid and lifelike. The table is surrounded by a chair, which is like a "hippo mother" holding a "baby hippo", also personified as a parent holding a child, reflecting parents' selfless love for their children. The children desk that a variety of functions combines, add a variety of use forms such as blackboard, receive drawer.

- Dimensional design

(1) Table size design

The size design of the table is mainly based on the size of children sitting for reference, the height of the table top to the ground refers to the height of children's elbows on the table into 90 degrees when the position to the ground; The space under the table refers to the thickness of the child's seat surface and thigh. According to the growing trend of height of children of different genders aged 2-6 years old, the optimal value was taken to design the size of the table. Finally, the length, width and height of the table are set as $850 \mathrm{~mm}, 550 \mathrm{~mm}$ and $650 \mathrm{~mm}$ respectively. The height of the space under the table is $400 \mathrm{~mm}$.

(2) Chair size design

The seat height of the chair refers to the height from the child's knees to the ground and the height of the space under the table; The width of the chair refers to the width of the space under the table; The height of the back of the chair refers to the distance from the child' s shoulders to the hips. In order to design the most comfortable seat for children, taking into account the height of children aged $2-6$, the seat surface height of the chair is finally set as $300 \mathrm{~mm}$, the overall height as $650 \mathrm{~mm}$, the length of the seat surface as $350 \mathrm{~mm}$, the width as $310 \mathrm{~mm}$, and the thickness of the backrest as $40 \mathrm{~mm}$. As shown in Figure 2 and 3 .
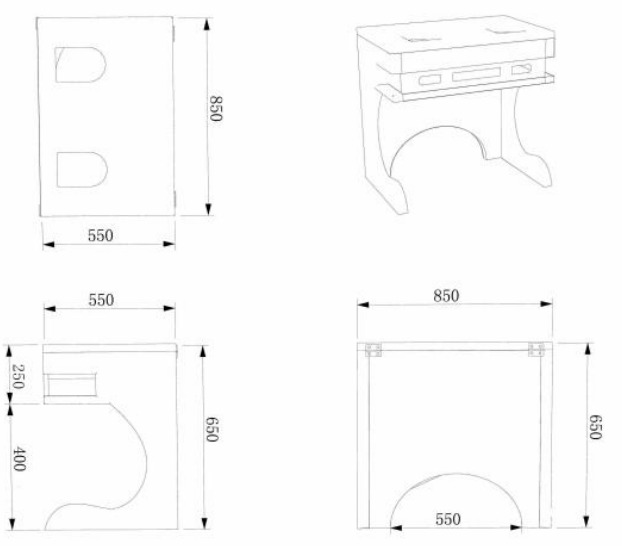

Figure 2 Table size drawing
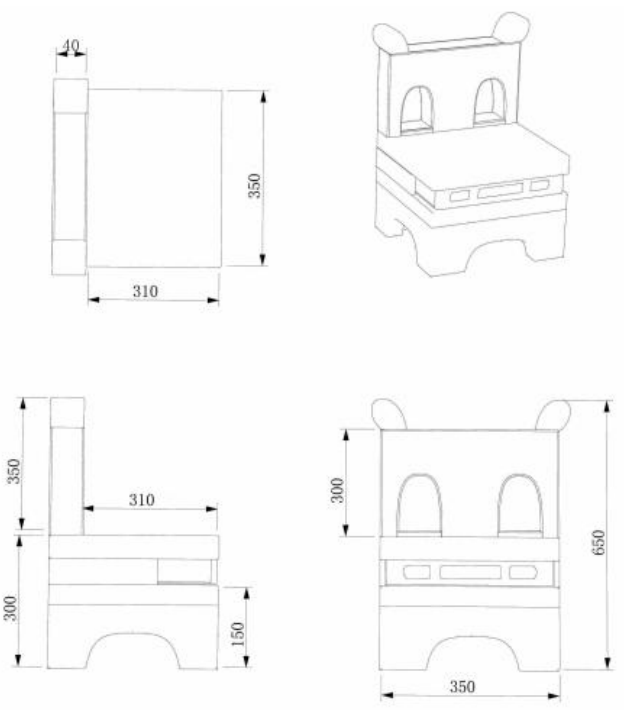

Figure 3 Chair size drawing

- Scheme deepening

(1) Functional design

The functional design of hippopotamus table and chair follows the principle of simplicity and ease of use[4]. On the basis of dimension design, ${ }^{2}$ the three-dimensional model and structure design of each part is carried out in 
combination with the degree of ease of operation of children. Establish a natural matching relationship between human and machine, let children explore by themselves through simple and understandable operation mode, and then select the most direct use mode to join the design. Safety remains Paramount in ensuring that children's attention and operations are engaged. Therefore, the table in the design of the clamshell, must ensure that the fixed parts of the use and opening and closing process is safe.

There is a white board pasted below the table cover for children to play freely. After desk cover is opened, it is the space that receive in desk belly, it is the shape of outline of face of a hippo, below deserve a drawer, hippopotamus two "eye" design becomes drawer handle, can place a few books, drawing paper to wait.

(2) Structural design

The height of children aged 2-6 is between 83.3 and $121 \mathrm{~cm}$, and the height difference of children in this age group is about $38 \mathrm{~cm}$. In order to enable children aged 2-6 to share the same set of desks and chairs, it is necessary to find the best size for their use.

Children' s furniture should be designed based on children's physical and psychological characteristics, and can meet children' s living, learning, entertainment and social needs, to provide them with sitting, storage and decoration needs of a kind of appliances[6]. Children's furniture on the market is creative but angular, which brings the risk of collision to children[7]. So children's products must be angular. This desk and chair adopts modular design, folding and pulling structure, modular design is mainly applied to the drawer, there is no connection of any parts, the way of use is direct pulling. The folding structure is applied to the table cover, which is connected by hinge parts and can be folded directly.

- Model making and display

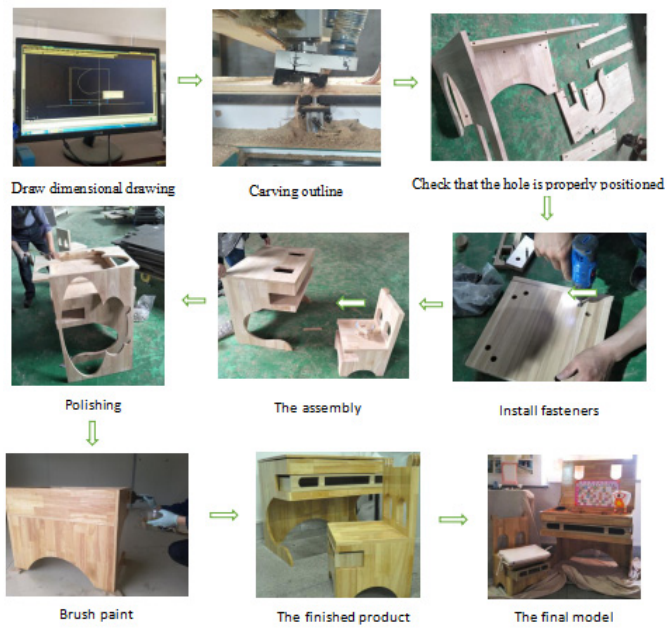

Figure 4 The production process

A 1:1 model is made, as shown in Figure4. To the product size, safety performance and man - machine repeated tests. As shown in Figure 5, the scene diagram of children using.

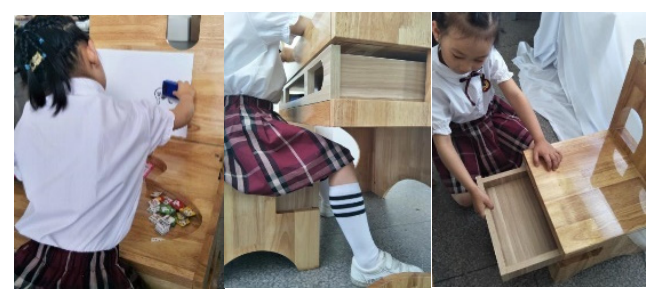

Figure 5 Ergonomic chart

- Material selection

Above all, furniture design must consider the bearing sex of the product, choose sedate and durable material; Secondly, the safety of children's products is the primary concern, the preferred material should be safe and nontoxic. Based on the above two points, the final material selected is mainly rubber wood, supplemented by multilayer board.

Sustainable design is to point to minimize the damage to the environment, the resources sustainable use for a long time, and at the same time enjoy the fairness of the offspring of resources, can continue to design not only to reasonable use of resources, as far as possible use less pollution to the environment, material consumption, less burden, but also efficient use of resources, as far as possible use of renewable materials, reasonable plan as much as possible to unsustainable consumption of materials[8].

\section{CONCLUTION}

The market prospect of children furniture design is optimistic, especially children are fully recognized in the process of using, which is very market and easy to be accepted. This paper focuses on the cognitive training of children with bionics as the auxiliary research and discussion. The combination of cognitive bionic cultivation and children furniture to the man-machine engineering, the function and characteristics, appearance of the product form, production technology and product solutions to determine the price into consideration and combining the product modelling, colour, material, function, etc., design a training for children cognitive, learning interest hippo bionic children furniture products.

\section{References}

1. Yu Dongjiu, Zhang Hao. Research on sustainable Design of Children's Furniture based on usability [J]. Packaging engineering,2016,37(14):109-112.

2. Zhang Wei. Research on Behavioral-AnalysisOriented Kindergarten Furniture Design [J]. Decoration,2018(09):126-127.

3. Zhao Wen. Applied Research on growth Concept in Children furniture Design [J]. Design,2018(22):114115.

4. Ding Yulan. Ergonomics [M]. Beijing: Beijing Institute of Technology Press, 2011.

5. Sheng Xin, Zhao Bi. Ergonomics based driving aid design for children with Cerebral Palsy [J]. 
Mechanical Design.1001-2353(2017)05-0119-05.

6. Cui Weiyao, Zhang Jianyi, Du Qiang, Ma Hongming, He Xiangzi. Application of 40 Invention Principles of TRIZ Theory in Children furniture Design [J]. Packaging engineering,2017,38(02):175-179.

7. Liu Yalu, Zhang Xiaoping. Emotional design of electronic products for school-age children based on behavioral patterns [J]. Furniture,2017,38(04):72-75.

8. pan xianglong, luo yinghuang. Research on sustainable design of children's furniture [J]. Packaging engineering,2016,37(08):94-97. 